\title{
Clinico-Pathological Profile of Gastric Cancer Patients Treated at Tertiary Care Cancer Hospital in Assam: Short Term Experience
}

\author{
B K Das', Ashish Gupta ${ }^{2}$, Anuj Sharma ${ }^{3}$, L Kalita ${ }^{4}$, K Bhuyan ${ }^{5}$ \\ ${ }^{1}$ Professor and HOD, Department of Surgical Oncology, Gauhati Medical College, Guwahati, ${ }^{2}$ Assistant Professor, \\ ${ }^{3}$ Junior Consultant, ${ }^{4}$ Assistant Professor, Department of Surgical Oncology, State Cancer Institute, GMC, \\ ${ }^{5}$ Professor, Department of Surgery, State Cancer Institute, GMC
}

\begin{abstract}
Background: Gastric cancers are among the commonest cancers in developing countries including India. Majority of the patients present in late stages of disease with dismal outcomes.

Materials and Method: Medical records of patients undergoing surgery for gastric cancer during 2018 were retrospectively analyzed. Clinical and pathological parameters were recorded and analyzed.

Results: Total of 49 patients were retrospectively analyzed. Most of the patients had advanced disease at presentation with anaemia in 40/49 (81\%) and Gastric outlet obstruction in 27/49 (55\%). 70\% of patients undergoing gastrectomy had node positive disease. There was a trend towards association between node positive disease and tumour thickness $>15 \mathrm{~mm}(\mathrm{p}=0.024)$.

Conclusion: Majority of gastric cancer patients in North East India present in advanced stage with anaemia and gastric outlet obstruction. Tumour thickness $>15 \mathrm{~mm}$ can possibly predict regional lymph node metastasis in gastric cancer patients.
\end{abstract}

Keywords: Gastric cancers, retrospective analysis, gastrectomy, anaemia, gastric outlet obstruction, regional lymph node metastasis, tumour thickness

\section{Introduction}

In India it is the fifth most common cancer among males and the seventh most common cancer among females1. The symptoms and sign of stomach cancer are often reported late when the disease is already in advanced stages and 5-year survival is less than 30\% in developed countries and around $20 \%$ in developing countries 1,2,3,4,5. Henceforth, detection of malignancy is of utmost priority to facilitate early intervention in form of surgery and/or chemotherapy. Clinical examination, endoscopy, and histopathological examination have been

\section{Corresponding Author:}

Dr Ashish Kumar Gupta

Assistant Professor, Department of Surgical Oncology

State Cancer Institute, GMC,

E mail: drashish_1001@yahoo.com

Contact No: 8826184015 the cornerstone of investigation of gastric malignancy3. This short term pilot study was undertaken to analyse the clinical and pathological profile of gastric cancer patients in Assam.

OBJECTIVE: To study the Clinico-Pathological profile of gastric cancer patients presenting at State Cancer Institute, Gauhati Medical College.

MATERIALS AND METHOD: Medical records of 49 patients undergoing surgery for gastric cancer at our institute during 2018 were retrospectively analysed.

Inclusion Criteria: 1) All patients with biopsy proven adenocarcinoma stomach undergoing surgery at our institute during 2017 were included. Exclusion: 1) Patients with biopsy other than adenocarcinoma (GIST, Lymphoma, Sarcoma) 2) Patients with incomplete medical records. 3) Patients presenting after surgery at other institute were not included. 
All the clinical and pathological parameters were recorded and retrospectively analysed. Statistical analysis was done using student's t test, Pearson chi square test and Fischer's exact test. P value $<0.05$ was considered as statistically significant.

\section{Results}

Demographic profile: Mean age was $54.73 \pm 11.64$ yrs (33-85 yrs). M:F ratio was 1.9:1. MC symptom was abdominal pain in $27 / 49(55 \%)$ patients. $32 / 49$ (65\%) patients were addicted to tobacco in some form.

Table 1 (Demographic profile)

\begin{tabular}{|l|l|}
\hline Age $($ Yrs $)(\mathbf{n}=\mathbf{4 9})$ & $\mathbf{5 4 . 7 3} \pm \mathbf{1 1 . 6 4}$ yrs $\mathbf{( 3 3 - 8 5}$ yrs $)$ \\
\hline Gender $(\mathrm{n}=49)$ & M:F:: $1.9: 1$ \\
\hline Tobacco addiction $(\mathrm{n}=49)$ & $\begin{array}{l}\text { Addicted } \mathrm{n}=32(65 \%) \\
\text { Not Addicted } \mathrm{n}=17(35 \%)\end{array}$ \\
\hline
\end{tabular}

\section{Clinical Presentation:}

Mean duration of symptoms was $3.68 \pm 2.77$ months (1-12 Months). Most common symptoms were abdominal pain in 27/49 (55\%), vomiting 17/49 (35\%) and GI bleed (Haemetesis/Malena) in 9/49 (15\%) patients respectively. Most common signs were anaemia $33 / 49(67 \%)$, gastric outlet obstruction in 20/49 (41\%) and palpable lump in 13/49 (18\%) patients respectively.

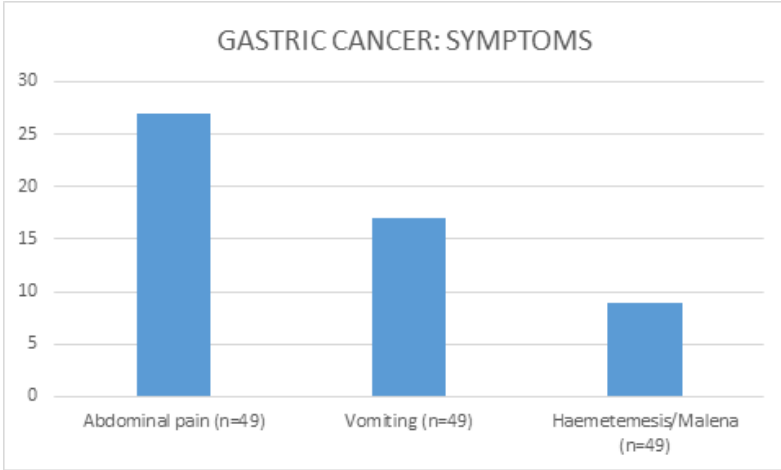

\section{Figure 1}

\section{GASTRIC CANCER: CLINICALSIGNS}

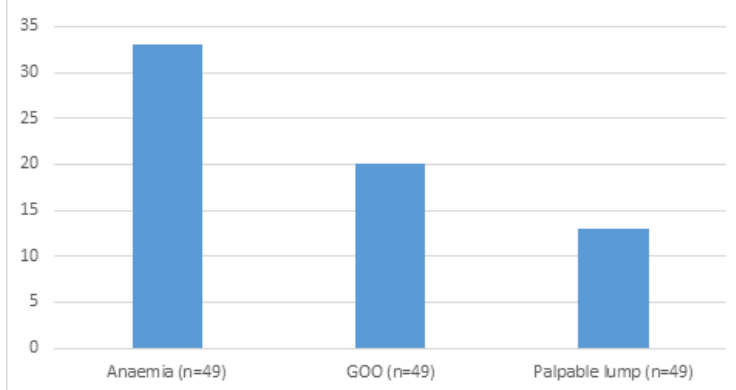

Out of all patients undergoing exploratory laparotomy, 30/49 (62\%) underwent Radical D2 gastrectomy whereas 19/49 (38\%) had palliative bypass. MC site was antropyloric region of stomach in 45/49 (91\%) patients. Out of 30 patients undergoing Radical gastrectomy, 15/30 (50\%) had node positive disease.

\section{Pathological profile:}

Majority of patients has poorly differentiated adenocarcinoma 20/38 (52\%). Most common WHO type was tubular in $31 / 38(81 \%)$ and poorly cohesive (signet ring) in $5 / 38$ (13\%) patients respectively. MC macroscopic type was ulcerative in 31/38 (81\%) patients. Mean Tumour thickness was TT $18.66 \pm 6.94$ $\mathrm{mm}(8-35 \mathrm{~mm})$. Out of 20 patients undergoing Radical D2 gastrectomy, $16(80 \%)$ were found to have regional lymph node involvement.

Table 2: (Pathological profile)

\begin{tabular}{|c|c|}
\hline HPE Grade $(n=49)$ & $\begin{array}{l}\text { Well Diff } n=13(28 \%) \\
\text { Mod diff } n=10(18 \%) \\
\text { PDC } n=26(52 \%)\end{array}$ \\
\hline WHO type $(n=49)$ & $\begin{array}{l}\text { Tubular } n=40(82 \%) \\
\text { Poorly cohesive (Signet ring) } n=7 \\
(14 \%) \\
\text { Papillary } n=1(2 \%) \\
\text { Mucinous } n=1(2 \%)\end{array}$ \\
\hline $\begin{array}{l}\text { Macroscopic } \\
\text { appearance }(n=49)\end{array}$ & $\begin{array}{l}\text { Ulcerative } n=40(82 \%) \\
\text { Fungating } n=4(7 \%) \\
\text { Infiltrative } n=4(7 \%) \\
\text { Polypoidal } n=2(3 \%)\end{array}$ \\
\hline $\begin{array}{l}\text { Tumour thickness (in } \\
\mathrm{mm} \text { ) }\end{array}$ & $16.4 \pm 5 \mathrm{~mm}$ \\
\hline Nodal status $(\mathrm{n}=30)$ & Node positive $n=15(50 \%)$ \\
\hline
\end{tabular}

\section{Univariate Analysis:}

On applying Fischer's exact test, a significant association was found between Tumour thickness> $15 \mathrm{~mm}$ with regional lymph node metastasis $(\mathrm{p}=0.024)$.

Figure 2 
Table 3 (Asssociation of Tumour thickness with Regional lymph node metastasis)

\begin{tabular}{|c|c|}
\hline Tumor thickness & Nodal status \\
\hline $\begin{array}{l}\text { Tumour Thickness }<15 \mathrm{~mm} \\
\mathrm{n}=1 / 30\end{array}$ & Node positive \\
\hline negative $n=11 / 30$ & Node \\
\hline \multirow[t]{2}{*}{$\begin{array}{l}\text { Tumour thickness } \geq 15 \mathrm{~mm} \\
\mathrm{n}=14 / 30\end{array}$} & Node positive \\
\hline & Node \\
\hline \multicolumn{2}{|c|}{$\mathrm{p}=0.024$ (Fischer's exact test) } \\
\hline
\end{tabular}

\section{Discussion}

Mean age of patients in our study was 54.73 years and M:F ratio 1.9:1 which were comparable to studies done by Sumantary, Nandi and Barad et $\mathrm{al}^{2,3,4} .65 \%$ of patients in our study addicted to tobacco. Throughout the world there is a male preponderance of the disease $^{6,7,8}$.This male preponderance of gastric cancer may be attributed to the high incidence of smoking among males as compared to female ${ }^{9}$. Most common site was antropyloric region of stomach (91\%) and was comparable to other studies ${ }^{1,2,3,4,5}$. Most common symptoms were abdominal pain and vomiting in 55\% and $35 \%$ patients respectively. In study done by Kasim et al, epigastric pain was the most common symptom (87\%) followed by weight loss and indigestion $72.5 \%$ and $69.6 \%$ respectively ${ }^{1}$. Study done by Barad et al found abdominal pain in $61.4 \%$ and vomiting in $20.9 \%$ patients as common symptoms ${ }^{4}$. Higher incidence of anaemia and GOO in developing countries can be explained by delayed presentation of patients in advanced stage of disease.

Majority of patients had poorly differentiated carcinoma $(52 \%)$. Ulcerative variety was found on grossing in $81 \%$ cases. Kassim et al and Samantaray et al found ulcerative variety in $73.9 \%$ and $73.1 \%$ patients respectively ${ }^{1,2}$. Mean tumour thickness was $16.4 \pm 5 \mathrm{~mm}$. $50 \%$ of patients had metastasis to regional lymph nodes on final histopathology specimens.

We also found a significant association between tumour thickness $\geq 15 \mathrm{~mm}$ and incidence of regional lymph node metastasis $(p=0.024)$. Sasagama et al found male gender, age ( $>40$ yrs), the depth of invasion, LVI, and tumour located in corpora or angle as independent risk factors for regional lymph node metastasis $^{6}$. In particular, lymph node status has been established as one of the most important criteria for proper treatment strategy and prognosis of gastric cancer preoperatively ${ }^{10,11}$. Lymph node (LN) status is the important prognostic factor regarding long-term survival in gastric cancer ${ }^{12}$. Pretreatment knowledge of LN status may help in selecting patients who might benefit most from neoadjuvant chemotherapy ${ }^{13}$. This is especially important as tumour thickness can be easily evaluated using imaging modalities like CT scan and MRI.

\section{Conclusions}

1) Anaemia and Gastric outlet obstruction are the commonest presentations of gastric cancer in our population.

2) MC site of disease is antro-pyloric region of stomach.

3) Majority of patients undergoing gastrectomy had node positive disease probably due to advanced stage at presentation.

4) There is a significant association between $\mathrm{TT} \geq 15 \mathrm{~mm}$ and probability of regional lymph node metastasis.

\section{Conflict of interest: Nil}

\section{Ethical clearance: Taken}

\section{Source of funding: Self}

\section{References}

1) Kassim A, Qubaty M. Clinicopathological Pattern of Gastric Cancer of Yemeni Patients in Ibb Governorate. Open Access Library Journal. 2018 March 7; 4415(5)

2) Samantaray S. Pattanayak L. Mohanty S. Clinicopathological Profile of Carcinoma Stomach An Institutional Experience of 350 patients. Journal of Medical Science and Clinical Research.2017; 5(1): 17167-17171.

3) Nandi A, Biswas PK, Kar M, Sinha S. Clinicopathological profile of gastric cancer in a tertiary care hospital in Eastern India A prospective 2 year study. Clinical Cancer Investigation Journal. 2014;3(1): 14-20 
4) Barad A, Mandal S, Harsha H, Sharma B. Gastric cancer - a clinicopathological study in a tertiary care centre of North-eastern India. J Gastrointest Oncol. 2014;5(2) :142-147

5) Takatsu Y, Hiki $\mathrm{N}$, Nunobi $\mathrm{S}$, Ohashi $\mathrm{M}$. Clinicopathological features of gastric cancer in young patients. Gastric Cancer. 2016; 19:472-478

6) Sasagama T, Solano H, Mena F. Gastric Cancer in costa rica. Gastrointest Endoscopy. 1999;50:594595

7) James CY, Jennifer FT, Samidha W, Kenneth RH, Paul FM, Christopher HC. Clinicopathological Behaviour of Gastric Adenocarcinoma in Hispanic patients Analysis of a single institution's experience over 15 years. J Clin Oncol.2005; 13: 3094-3103

8) Seong Ho K, Do JP, Hyuk JL, Hyun CJ, Kuhn UL, Kuk JC, et al. Clinicopathologic features of asymptomatic gastric adenocarcinoma patients in Korea. Jpn J of Clin Oncol. 2004;34(1): 1-7
9) Arun Kumar Barad, Sanjeet Kumar Mandal, Hriyur S Harsha, Birkumar M. Sharma and Th Sudhirchandra Singh. Gastric Cancer-a clinicopathological study in a tertiary care centre of North eastern India. J Gastrointest Oncol.2014 Apr; 5 (2): 142-147

10) Japanese Gastric Cancer Association. Japanese classification of gastric carcinoma. Gastric Cancer $3^{\text {rd }}$ english edition.2011; 14(2):101-112

11) T. Sano, O. Kobori, and T. Muto. Lymph node metastasis from early gastric cancer: endoscopic resection of tumour. British Journal of Surgery.1992;79(3) :241-244

12) Kwee RM, Kwee TC. Imaging in assessing lymph node status in gastric cancer. Gastric Cancer. 2009;12:6-22.

13) De Vita F, Giuliani F, Galizia G, et al. Neo-adjuvant and adjuvant chemotherapy of gastric cancer. Ann Oncol. 2007;18(6):120-3. 